\title{
LA TEORÍA DEL TÍTULO VÁLIDO DE ROBERT NOZICK: UN BALANCE*
}

\author{
Felipe Schwember
}

Universidad Adolfo Ibáñez

\begin{abstract}
Resumen: La teoría del título válido constituye uno de los ejes de la teoría de la justicia de Robert Nozick. Como pilar del argumento en defensa de un Estado mínimo, ha sido objeto de diversos ataques. El presente trabajo examina algunas de las críticas que se le han dirigido con el objetivo de demostrar que muchas de ellas son febles o descansan en malentendidos que pueden ser evitados con una adecuada interpretación de la estipulación de Locke o del principio de rectificación. Se concluye, empero, que una consideración realista de las condiciones a las que debe ser aplicada la teoría del título válido debiera conducir a la necesidad de defender un Estado más que mínimo, e incluso por más tiempo del que Nozick está dispuesto a admitir.
\end{abstract}

Palabras clave: Nozick, teoría del título válido, propiedad, libertarismo.

RECIBIDO: junio 2015; ACEPTADO: septiembre 2015.

Felipe Schwember. Licenciado en derecho y en filosofía por la Universidad Católica de Chile. Doctor en filosofía por la Universidad de Navarra. Profesor del Centro de Investigación en Teoría Social y Política de la Escuela de Gobierno, Universidad Adolfo Ibáñez. Email: felipe.schwember@uai.cl.

* El presente artículo forma parte del proyecto Fondecyt de iniciación n. ${ }^{\circ} 11130057$ titulado "La recepción de Kant en las teorías de la justicia contemporánea: Rawls y Nozick". El autor agradece la lectura de Gonzalo Cordero Mendoza, Miguel González Vallejos y de los evaluadores anónimos de Estudios Públicos. Sus sugerencias contribuyeron a mejorar significativamente este artículo. 


\section{NOZICK'S ENTITLEMENT THEORY: AN ASSESSMENT}

ABSTRACT: Robert Nozick's entitlement theory is one of the cornerstones of his theory of justice. Being one of the pillars of the argument in the defense of a minimal State, it has been a target for much criticism. This article studies some of these attacks in order to show that many of them are either misguided, or are based on misunderstandings which are eliminated through an adequate interpretation of the function played by Locke's proviso and the principle of rectification within Nozick's theory. In discussing these principles, though, the article put forward the reading that a realist consideration of the conditions under which an entitlement theory should be applied would entail a defense of a more than minimal State, for much longer than Nozick would admit.

KEYwords: Nozick, entitlement theory, property, libertarianism.

RECEIVED: June 2015; ACCEPTED: September 2015.

\section{INTRODUCCIÓN}

A 1 comparar el sitial en la filosofía política contemporánea que ha alcanzado Anarquía, Estado y utopía de Robert Nozick (en adelante $A S U$, por su sigla en inglés), ${ }^{1}$ cuya recepción ha sido tan amplia como crítica, es imposible no experimentar cierta perplejidad. Por una parte, es ampliamente aclamada como la obra que — en la estela de Teoría de la justicia de Rawls - resucitó la filosofía política del prolongado letargo en que se encontraba desde los albores del siglo $\mathrm{XX}$; por otra, sin embargo, parece ser una obra que no cuenta casi con simpatizantes, ni aun entre las filas de aquellos que se declaran libertarios.

Su recepción ha sido generalmente adversa, de modo que es una obra que se cita profusamente pero con el propósito casi exclusivo de refutarla, a veces de modo incluso algo destemplado (ver por ejemplo, Barry 1997, 178). Esta recepción más bien hostil - y que se ve rematada por el distanciamiento que el mismo Nozick tomó de esta obra en trabajos posteriores $(1989,286-287 ; 1995,56)$ - permite afirmar que la situación de $A S U$ es como la de una estrella solitaria que brilla inten-

${ }^{1}$ Las citas de $A S U$ están tomadas de la edición castellana (Nozick 1988), que se adopta con algunas correcciones. Las obras de autores clásicos como Aristóteles o Kant se las cita del modo canónico. 
samente en el firmamento de la filosofía política contemporánea, pero cuya luz sólo suscita antipatía.

La impopularidad de la obra se explica por la tesis de fondo que sostiene: que el Estado mínimo — esto es, el Estado limitado a la realización de funciones de policía y administración de justicia - es el único Estado moralmente admisible.

Nozick intenta sostener esta tesis a través de un doble razonamiento. Por una parte $-\mathrm{y}$ contra el así llamado "anarquista individualista"trata de demostrar, mediante una narración hipotética, la posibilidad teórica de que el Estado hubiese podido surgir sin lesionar los derechos de nadie, como resultado inintencionado de una serie de acuerdos de protección mutua. Por otra $-\mathrm{y}$ con ello se pasa a la segunda parte de la obra-, Nozick intenta demostrar la ilicitud de cualquier Estado mayor que el Estado mínimo. Esta última demostración se ofrece fundamentalmente a partir de la llamada teoría del título válido (entitlement theory), que se ha convertido por ello en uno de los blancos preferidos de los detractores de Nozick.

El presente trabajo se detiene precisamente en este flanco de la teoría de Nozick, en la teoría del título válido, para quebrar algunas lanzas en su favor. Para eso, en primer lugar, se examinarán algunas de las críticas que sus detractores le han dirigido. Como se espera poner de manifiesto, muchas de esas críticas son francamente febles, mientras que otras descansan en asunciones tan gruesas como injustificadas acerca de lo que es la propiedad.

Por lo mismo, como se espera probar, una consideración imparcial y desapasionada de la teoría del título válido debiera reconocerle mucho más crédito del que generalmente se le concede, en el sentido de ser no sólo una teoría ingeniosa, sino de ser también una teoría plausible de la justicia. Aquí se sostendrá que dicha plausibilidad depende, en lo fundamental, de dos aspectos de la teoría que han sido generalmente pasados por alto por los críticos.

El primero de ellos es el tratamiento de la necesidad que Nozick hace a propósito de la estipulación de Locke. Varios aspectos polémicos — por no decir escandalosos - de la teoría del título válido se disipan al considerar la función que en ella le cabe a la estipulación de Locke o, en su defecto, al ethos de tolerancia que, en el espíritu del liberalismo, sirve de contexto a la teoría de la propiedad de Nozick. 
El segundo tiene que ver con la función y alcance del último principio de la teoría del título válido: el principio de rectificación. Se sostendrá que, dada la brecha entre las condiciones ideales de intercambio a que apela la teoría y las condiciones reales conforme a las cuales se distribuyen efectivamente los bienes, el principio de rectificación autoriza a la instauración de un Estado más extenso que el Estado mínimo defendido por Nozick. Por ello, la defensa de la teoría apela más bien aquí a la teoría posible - esto es, a aquello que podría haberse seguido de ella de haberse tenido en cuenta sistemáticamente esta brecha- que a la teoría efectivamente presentada en $A S U$. Como se espera demostrar, esta versión posible de la teoría es consistente y, más aún, viene exigida por los principios libertarios por los que se orienta el propio Nozick.

\section{LA TEORÍA DEL TÍTULO VÁLIDO}

La teoría del título válido (conocida también como la "teoría del título posesorio") es enunciada por Nozick en la segunda parte de $A S U$ del siguiente modo:

Si el mundo fuera completamente justo, las siguientes definiciones inductivas cubrirían exhaustivamente la materia de justicia sobre pertenencias.

1) Una persona que adquiere una pertenencia, de conformidad con el principio de justicia en la adquisición, tiene derecho a esa pertenencia.

2) Una persona que adquiere una pertenencia de conformidad con el principio de justicia en la transferencia, de algún otro con derecho a la pertenencia, tiene derecho a la pertenencia.

3) Nadie tiene derecho a una pertenencia excepto por aplicaciones (repetidas) de 1 y 2.

El principio completo de justicia distributiva diría simplemente que una distribución es justa si cada uno tiene derecho a las pertenencias que posee según la distribución. (Nozick 1988, 154)

Estos principios deben ser completados con el principio adicional que establece que una persona tiene un justo título para recuperar la posesión de un bien que le ha sido injustamente arrebatado (principio de rectificación). 
En consecuencia, la teoría del título válido consta de tres principios: el principio de justicia en la adquisición, el principio de justicia en la transferencia y el principio de rectificación. Estos principios son meramente formales y son verdaderos por definición, pues no vienen a decir sino que la posesión de una pertenencia es justa cuando su adquisición también lo ha sido. ${ }^{2}$

Antes de aclarar, por tanto, en qué consiste la "justicia" a que los diferentes principios se refieren, resulta difícil determinar qué cosas pueden suponerse o implicarse con ellos. De hecho, tales principios podrían ser formulados de modo que condujeran, por ejemplo, a una teoría de la justicia como la de John Rawls. Esto explica que los detractores de la teoría del título válido, por regla general, no hayan intentado negar dichos principios, sino más bien subrayar las dificultades o inconvenientes que se seguirían de su aplicación (ver, por ejemplo, Cohen 1995) o, en fin, disputar la interpretación y alcance que el propio Nozick hace de los mismos.

En todo caso, de su mismo enunciado es meridianamente claro que la teoría del título válido se refiere a la posesión de los bienes externos y no a otra cosa, por lo que resulta desconcertante que se haya dicho que la teoría es incompleta porque en su formulación no se aclara el tipo de derechos que los individuos tienen sobre sí mismos (Vallentyne 2011, 152). Como sucede en otras teorías iusnaturalistas, Nozick se ha referido a tales derechos antes de presentar la teoría de la propiedad (es decir, en la primera parte del libro). Este orden en la exposición obedece a una necesidad lógica: los derechos individuales constituyen una condición de posibilidad de la teoría de la propiedad sobre los bienes externos. Esta precedencia explica también el que no se suela considerar que la teoría general de los derechos individuales forme parte, en rigor, de la teoría de la propiedad (ver, por ejemplo, Kant, AA VI, 236238).

Ahora bien, ¿cómo debe interpretarse la teoría del título válido? Nozick se encarga de aclarar que los principios de su teoría de la pro-

\footnotetext{
${ }^{2}$ Por ejemplo, respecto del principio de justicia en la adquisición, dice Nozick: "Cualquier cosa que surge de una situación justa, a través de pasos justos, es en sí misma justa"; respecto del principio de justicia en las transferencias dice: "Una distribución es justa si surge de otra distribución justa a través de medios legítimos" (Nozick 1988, 154-155). Cabría preguntarse, ¿en qué sentido estas proposiciones — que resumen la teoría del título válido_ pueden ser falsas?
} 
piedad deben ser entendidos en un sentido puramente histórico. Esto significa, en primer lugar (y siguiendo su propia nomenclatura), que la suya no es una teoría de resultado final, esto es, una teoría según la cual "la justicia de una distribución está determinada por cómo son distribuidas las cosas (quién tiene qué) juzgando de conformidad con algún(os) principio(s) estructural(es) de distribución justa” (Nozick 1988, 157).

Por el contrario, por ser histórica, la teoría afirma que no es posible determinar si alguien tiene derecho (un título) a la posesión de un determinado bien sin saber antes cómo es que ha llegado a tener dicha posesión: "Los principios históricos de justicia sostienen que las circunstancias o acciones pasadas de las personas pueden producir títulos diferentes o merecimientos diferentes sobre las cosas" (Nozick 1988, 158). Pero además, aclara Nozick, la suya no sólo es una teoría histórica, sino que, además, es una teoría histórica y no pautada. Este alcance permite ahora introducir una subdivisión de las teorías históricas en teorías históricas pautadas y no pautadas.

Las primeras son aquellas que determinan "que la distribución debe variar de conformidad con alguna dimensión natural, con la suma de pesos de las dimensiones naturales de conformidad con un orden lexicográfico de dimensiones naturales. Permítasenos decir, además, que la distribución es pautada si se conforma con algún principio pautado" (Nozick 1988, 159). Así, una teoría que estableciera que ha de darse a cada uno según su virtud moral sería una teoría histórica y pautada. "Histórica", pues no puede saberse si alguien es virtuoso o no sin atender a lo que ha hecho; y "pautada", porque la distribución debe variar de acuerdo con la posesión de las virtudes requeridas (que además podrían ordenarse lexicográficamente). Nozick se apresura a aclarar que la suya es una teoría histórica y no pautada y que, en consecuencia, si de lo que se trata al formular una teoría de la justicia es de llenar los blancos en "de cada uno según su

y para cada uno según su ", entonces debiera serlo en los siguientes términos: "de cada uno según escoge, a cada uno según es escogido” (Nozick 1988, 163). Esto viene a significar que una distribución es justa si, simplemente, es el resultado de los acuerdos libres y voluntarios que celebran los agentes.

Como una teoría puramente histórica y no pautada habrá de resultar controversial, Nozick se apresura a ofrecer un argumento en su 
favor: imagine una distribución cualquiera $\mathrm{X}$ y dé al mismo tiempo a los individuos el derecho a decidir qué hacer con la porción que les ha tocado; imagine, asimismo, que Wilt Chamberlain es un jugador famoso de baloncesto, de suerte que muchos de ellos quieren verlo jugar, destinando para ello un porcentaje $\mathrm{X}_{1}$ de su respectiva porción. En virtud de la libertad de los diferentes individuos para disponer de su porción, es claro que la distribución inicial $\mathrm{X}$ no puede ser mantenida sin impedir o gravar constantemente ciertas transacciones. La idea detrás del argumento es que, afirma Nozick, ninguna pauta distributiva puede ser establecida sin interferir constantemente en la libertad de la gente. De este modo, los partidarios de las pautas se ven en la necesidad de prohibir "actos capitalistas entre adultos que consienten" (Nozick 1988, 165).

Llegados a este punto, resulta conveniente decir que, aun cuando pudiera parecer escandalosa, la teoría del título válido no puede ser del todo errónea pues refleja las reglas generales del derecho privado (esto es, las reglas generales conforme a las cuales deben tener lugar los intercambios entre particulares). Por eso, a lo sumo podría decirse, no que la teoría histórica y no pautada de Nozick es sin más errónea, sino que es defectuosa porque necesita ser completada por alguna pauta, por ejemplo, en favor de aquel que padece necesidad.

No obstante, y como veremos, Nozick intenta salvar el problema de la necesidad por la vía de exigir ciertos requisitos a las adquisiciones originarias y derivativas. Aunque se podría ciertamente discutir si ésa no es una forma de introducir subrepticiamente una pauta, baste por ahora decir que, dado que Nozick sí considera el caso de aquel que padece necesidad, el hecho de que su teoría recoja in nuce todas las reglas del derecho privado es un motivo suficiente para considerarla, al menos prima facie, como una teoría adecuada de la propiedad.

Por eso es todo un logro de Nozick que una de sus críticos, Onora O'Neill, se haya visto en la necesidad de admitir que una sociedad socialista efectivamente necesita prohibir los "actos capitalistas entre adultos que consienten" (O’Neill 1981, 309). Esa desenfadada afirmación debiera constituir un motivo de vergüenza para aquellos que, por otra parte, dicen deplorar las políticas paternalistas. 


\section{EL CONCEPTO DE PROPIEDAD}

La afirmación de O'Neill arranca, en último término, de una determinada concepción de la propiedad en que merece la pena detenerse, aunque fuere someramente, pues muchas de las críticas dirigidas a Nozick arrancan de dicha concepción (ver, por ejemplo, O’Neill 1981; Nagel 1981; Vallentyne 2011).

O'Neill reprocha a Nozick haber presupuesto un cierto concepto de propiedad, un concepto que puede denominarse "pleno" de propiedad. Sin perjuicio del tenor general del texto de Nozick, hay una prueba explícita de que Nozick apela a ese concepto preciso de propiedad cuando afirma: "El núcleo central de la noción de un derecho de propiedad sobre $\mathrm{X}$, en relación con qué otras partes de la noción se deben explicar, es el derecho a determinar qué es lo que se debe hacer con X" (Nozick 1988, 172).

Pero este concepto de propiedad, dice O'Neill, requiere justificación. La razón de ello estriba en que el concepto de propiedad consistiría en realidad en un haz de derechos (bundle of rights), entre los que se incluye el control sobre la cosa, el derecho de excluir a otros, de usarla, de aprovechar sus frutos o rentas, etcétera (Honoré, 1961); el hecho de que la propiedad sea la suma de diferentes derechos es una prueba de que el concepto pleno de propiedad es más bien una rareza desde un punto de vista empírico y que Nozick hace mal en presuponerlo.

El paradigma de la propiedad del que parte O'Neill corresponde al así denominado paradigma analítico de la propiedad, muy en boga en el mundo anglosajón desde que fuera introducido por Honoré siguiendo los análisis de Hohfeld (1964). Resulta tentador suponer que la amplia recepción de este paradigma entre los autores igualitarios se deba a que resulta fácil de compaginar con los supuestos del contractualismo: si la propiedad no es más que un conjunto de derechos y los derechos se tienen por definición en contra de otras personas (y a su vez yo no puedo tener derechos sobre/contra otro sino en virtud de su consentimiento), resulta natural ver en el paradigma analítico una explicación convencionalista de la génesis y legitimidad de la propiedad: "Lo tuyo es tuyo porque todos convenimos en que así sea".

No obstante, el paradigma analítico adolece de varios defectos y sus partidarios lo asumen demasiado rápido y demasiado acríticamen- 
te. Puesto que no es posible mencionarlos todos, y menos aún hacerlo detalladamente, resumiré algunos de sus problemas en las siguientes líneas: ${ }^{3}$

1) El paradigma analítico disuelve el concepto de propiedad en una serie de ius in personam, o derechos personales (Grey 1980).

2) El concepto de propiedad pleno que el paradigma analítico tiende a disolver es, por otra parte, irreductible. Alguien (sean uno o muchos) debe tener finalmente la capacidad de disposición de las cosas (el ius abutendi). Lo que ocurre sencillamente es que mientras más titulares tenga dicha capacidad, más repartida se encontrará y, en consecuencia, menos posibilidad tendrá cada uno de ellos de hacer uso libremente del bien del que se trata (más permisos y autorizaciones serán requeridos para ello). A mayor división del derecho, menor libertad.

3) El paradigma analítico introduce y supone una confusión entre lo que la propiedad es (un derecho sobre una cosa) y el modo en que la propiedad debe ser justificada (la justificación de su efecto erga omnes, es decir "frente a todos"). La propiedad supone efectivamente una vinculación jurídica entre personas (más precisamente, entre el dueño y todo el resto del mundo con respecto a la cosa poseída), pero de esta constatación elemental no se sigue, ni necesita seguirse, el paradigma analítico como explicación de lo que la propiedad es y de las razones por las cuales resulta obligatoria.

En consecuencia, resulta temerario acusar a Nozick de haber presupuesto un cierto concepto de propiedad "plena". Probablemente es más cierto que la (defectuosa) nomenclatura de Honoré ha sembrado una gran confusión acerca de lo que la propiedad es, alentando de paso con ello críticas como las de O'Neill o Nagel a Nozick. Por otra parte, es difícil no suponer que el paradigma analítico de la propiedad descansa, aunque fuere de modo implícito, en alguna forma de comunidad positiva (originaria o adventicia). A propósito del principio de justicia en la adquisición, nos referiremos a continuación a la teoría de la comunidad originaria positiva.

${ }^{3}$ Para una crítica exhaustiva, ver Penner (1995-1996); Underkuffler (2003) y Schwember (2013). 


\section{PRINCIPIO DE JUSTICIA EN LA ADQUISICIÓN}

\section{a) El estado de comunidad originaria}

La enunciación del principio de justa adquisición resulta esencial para cualquier teoría histórica de la propiedad, pues su contenido determinará decisivamente la forma general de la misma. Y con vistas a tal enunciación pueden barajarse básicamente dos alternativas: una convención originaria o un modo unilateral de adquisición del dominio.

Por ejemplo, las teorías pre-lockeanas suelen explicar y justificar la introducción de la propiedad por medio de una convención tácita universal: la propiedad se introdujo de modo paulatino en virtud de las ventajas que la división de los bienes suponía para todos. En virtud de ciertas dificultades en las que aquí no podemos detenernos, la teoría del origen convencional de la propiedad fue paulatinamente abandonada dentro de la tradición iusnaturalista. Baste simplemente decir que la apelación a la conveniencia como razón de la división de los bienes termina por volver superflua la apelación al consenso universal (a la convención), especialmente cuando se asume que dicho consenso no puede haber tenido lugar de modo efectivo. Además, en sus explicaciones acerca de la génesis de la propiedad, tales teorías suelen entender que, junto con la división, los contratantes acordaban también que el modo de adquirir el dominio en lo sucesivo sería la prima occupatio, con la reserva de que aquellos que padecieran necesidad pudiesen hacer uso de aquello que necesitaban para vivir. ${ }^{4}$ Esto nos sitúa ya en el umbral de las teorías iusnaturalistas modernas que han abandonado el paradigma convencionalista de la propiedad.

Las teorías de Locke y de Kant pueden ser vistas como intentos de explicar la obligatoriedad universal de la propiedad (su así llamado efecto erga omnes o universal) sin recurrir a la ficción de la convención originaria. Pues bien, supongamos entonces con dichos autores que las posibilidades para una teoría histórica de la propiedad se reducen al final a dos: la prima occupatio y el trabajo. Nozick, siguiendo a Locke, se decanta por esta última. El razonamiento entonces es el siguiente: es

${ }^{4}$ Acerca de las razones generales a favor de la propiedad, ver Tomás de Aquino, $S T$., II-IIae, q. 66, a.2; con respecto a la división mediante la occupatio, ver De Soto, DII, IV, q. 3, a. 1 y Pufendorf, $J N G$, IV, §5, 9-17. 
lícito adquirir un bien que carece de dueño mediante el trabajo si con mi apropiación $-\mathrm{y}$ aquí hay varias posibilidades según cómo se interprete la teoría de Locke - a) dejo otro tanto de igual calidad para los demás; o b) no me apropio más de aquello que puedo aprovecharme; y/o c) con mi apropiación no empeoro la situación de los demás.

Antes de referirnos a estas condiciones, nos referiremos al primer supuesto que está incluido en el enunciado, a saber, que las cosas carecen originariamente de dueño (o, como se suele también decir, son $a b$ initio res nullius). Nozick parte precisamente de este supuesto y, sorprendentemente, se lo ha criticado por ello (ver, por ejemplo, Cohen 1995, 83-84, 92 y ss.; Queral y Gargarella en Cohen 2014, 15; Roar 2013, 13 у 63).

Pues bien, tiremos de la hebra que deja suelta la crítica a Nozick. ¿Cómo debemos representarnos la situación inicial de los bienes? En principio, hay dos posibilidades: todo es de todos o nada es de nadie. Ahora bien, "todo es de todos" (la llamada "comunidad originaria positiva") admite distintas interpretaciones. Todo es de todos puede querer decir que las cosas son comunes en el sentido de que todos y cada uno son dueños del total; o puede querer decir que todos y cada uno son dueños de una cuota del total; o finalmente puede querer decir que todos y cada uno son dueños de alguna parte indeterminada del total.

Por su parte, "nada es de nadie" (o la "comunidad originaria negativa") no puede sino querer decir que los bienes carecen originariamente de dueño y que todos tienen, por tanto, igual libertad de usarlos y apropiárselos (esto es, no es justo impedir a priori a alguien la adquisición de un bien que carece de dueño). ¿Cuál alternativa de entre todas estas es la preferible, la correcta?

Los autores medievales y modernos que se plantearon este problema (y que debían, además, contar como un hecho cierto e indubitable la donación universal de los bienes por parte de Dios a la humanidad que se relata en el Génesis) llegaron a la conclusión de que la comunidad positiva ("todo es de todos") no podía nunca ser considerada como originaria, sino sólo como instituida o adventicia.

Es decir, a este respecto, y por sorprendente que parezca, los teólogos medievales y los filósofos de la modernidad temprana coinciden en este punto particular con Nozick, pese a los presupuestos teológicos que necesitan tener en cuenta ¿Por qué? Hay varias objeciones a la idea 
de que pueda haber una comunidad originaria positiva. En primer lugar, si ése fuera el caso, la introducción de la propiedad sólo hubiese podido tener lugar mediante una convención unánime y expresa, de suerte que hubiera bastado con la oposición de uno de los comuneros para tener que permanecer en estado de indivisión (lo que, como decían los teólogos medievales, resulta imposible para personas como nosotros, que tenemos una naturaleza corrompida por el pecado).

Ahora bien, la primera hipótesis de comunidad originaria positiva mencionada arriba (todos y cada uno dueños solidariamente del total) es el blanco principal de esta crítica, y en ella es seguramente que piensa Locke cuando dice que si hubiese sido necesario un acuerdo universal en orden a la división de los bienes, la humanidad hubiese muerto de hambre a pesar de toda la abundancia con que Dios la proveyó (Locke, II, §28, 14-16).

La segunda hipótesis (todos y cada uno son dueños de una cuota del total) debe enfrentar el siguiente problema: ¿cómo puede saberse cuál es la cuota de cada uno? Si se toma eso en un sentido estricto, la división se torna imposible, pues para proceder a ella habría que conocer el abasto total de bienes del mundo. Queda entonces únicamente la tercera hipótesis (cada uno es dueño de una parte indeterminada del total), y ella se ve expuesta a una última crítica, que alcanza también a todas las otras hipótesis de la comunidad originaria de bienes: los individuos no pueden ser considerados como originariamente dueños ni individual ni conjuntamente de los bienes de la Tierra (de la "Creación") por la sencilla razón de que la propiedad no es un hecho de la naturaleza, un producto natural, sino una institución jurídica, esto es, una particular realidad sobreviniente que regula las relaciones entre los hombres.

Vinculado con este error, es posible indicar otro, fatal, de carácter metódico, en el que incurren las teorías que parten de una comunidad originaria positiva: presuponer aquello que precisamente necesitan probar. Como afirma Weinrib $(2003,822)$, la tarea de una filosofía del derecho consiste no en demostrar cómo se transita de una pretendida propiedad originaria común a un régimen de propiedad privado, sino que en cómo se puede instituir la propiedad a partir de un estado originario de no propiedad (ver también Fesser 2005).

En atención a este mismo problema, los iusnaturalistas clásicos concebían la comunidad originaria como una comunidad negativa, esto 
es, como una comunidad de hecho y no como una comunidad jurídica, y describían en consecuencia la situación originaria como una posesión común originaria y no como una propiedad común originaria. Al reprochar a Nozick el "haber asumido injustificadamente" que los bienes son originariamente res nullius, sus críticos caen en un error advertido de modo incesante desde el medioevo pre-tomista a la modernidad prekantiana. Por eso, al dirigir ese reproche a Nozick se ven expuestos a todas las demoledoras objeciones que los autores iusnaturalistas de la diversa índole han elevado contra la teoría de la comunidad originaria positiva de bienes.

En consecuencia, una vez desechada la teoría de la comunidad originaria positiva de bienes, la alternativa que queda — tal como ha sido entendido invariablemente - es la comunidad originaria negativa de bienes, es decir, la alternativa de la que precisamente parte Nozick para elaborar su teoría de la propiedad.

¿Qué implica esta última forma de comunidad? Como se adelantaba, se trata de una comunidad de hecho en que lo es que es común es la posesión de los bienes, no su propiedad, y en el que en consecuencia los individuos tienen la libertad de usar las cosas y de servirse de lo que otros han adquirido cuando la necesidad no culpable los obliga a ello. Como veremos, esa misma posibilidad es contemplada por Nozick en $A S U$.

\section{b) La estipulación de Locke}

Puesto que en un principio los bienes carecen de dueño, los individuos pueden apropiárselos mediante un modo unilateral de adquisición del dominio. Nozick sigue en esto a Locke con su teoría del "valortrabajo": me hago dueño de aquello que "mezclo" con mi trabajo. La presuposición de la teoría (además de la comunidad originaria negativa) es que se puede transitar de la no propiedad a la propiedad de los bienes externos a partir de una propiedad originaria: la propia persona (el propio cuerpo, el propio trabajo, etcétera).

La teoría del valor-trabajo presenta muchas dificultades, algunas de las cuales son indicadas por el propio Nozick en $A S U$ (1988, 175176). Aquí no nos podemos detener en ellas. Baste decir que Nozick las pasa por alto para concentrarse en las condiciones que deben cumplirse 
al momento de la adquisición para que ésta dé origen a la propiedad. Ésas son las llamadas "estipulaciones de Locke" y la interpretación que Nozick hace de ellas le ha valido las críticas tanto de los así llamados "libertarios de izquierdas" como de los "libertarios de derechas" y anarco-capitalistas.

Los partidarios de estas dos últimas corrientes básicamente critican a Nozick por incluir la estipulación de Locke como requisito de la licitud de una adquisición originaria (ver Rothbard 1995, 330; Narveson 2001, 84). Los partidarios de la primera, en cambio, por incluir una estipulación demasiado débil (ver Cohen 1995, 74 y ss.; Vallentyne 2011, 160).

Antes de examinar estas críticas, detengámonos en las razones que da Nozick para incluir la estipulación, así como la formulación que ofrece de la misma. ¿Por qué ha de incluirse una estipulación? Nozick observa que al apropiarme de un objeto cualquiera cambió la situación de todos los demás, que se ven privados de la libertad de adquirir ese mismo objeto (Nozick 1988, 176). Si este efecto en la libertad de los demás constituyera un empeoramiento de su situación, entonces mi apropiación debiera ser considerada como ilícita.

Por eso, el problema esencial "es si la apropiación de un objeto no poseído empeora la situación de otros" (Nozick 1988, 176). Ahora bien, Nozick observa que "empeorar" puede entenderse en este contexto en dos sentidos. Según el primero, que él denomina "fuerte", la apropiación de una res nullius empeora la situación de otros cuando los priva de la posibilidad de mejorar su propia situación por medio de la apropiación de lo que me apropio yo. Evidentemente, este sentido de "empeoramiento" debe ser rechazado, pues si la teoría del derecho se guiara por él debería proscribirse toda apropiación.

En un sentido "débil", en cambio, "no empeorar" significa, no reducir las posibilidades de apropiación, sino tan sólo reducir las posibilidades que tiene(n) otro(s) de usar algo. En consecuencia, la estipulación es introducida para salvar los derechos de terceros (y, con ello, la legitimidad de las apropiaciones). Por tanto, según este sentido débil, la apropiación de una res nullius es lícita cuando con ella no se empeora la situación de los demás privándolos de las posibilidades de usar otras cosas de esa misma clase de las que yo me apropio. Cuando dichas posibilidades no quedan salvadas debido a la escasez dramática de un 
recurso (como en el caso de la fuente de agua en el desierto o del náufrago que llega a las costas de una isla habitada o, en fin, de aquel que queda encerrado en su propiedad por la propiedad de todos los otros) (Nozick 1988, 63, nota al pie), ${ }^{5}$ entonces la estipulación opera en favor del necesitado para que satisfaga su necesidad apremiante. Considerando que la estipulación permite a una teoría histórica de la propiedad hacer frente al problema del que padece necesidad, no resulta sorprendente que Nozick concluya que "cualquier teoría adecuada de justicia de la adquisición contendrá una estipulación similar a la más débil de las dos que hemos atribuido a Locke" (Nozick 1988, 179).

Como se adelantaba, a propósito de las condiciones de la adquisición originaria, Nozick ha recibido críticas desde la "derecha" y desde la "izquierda". Entre los detractores de "derechas", Rothbard ha afirmado que "la estipulación de excepción de Locke puede conducir a la ilegitimación de todas las propiedades de la Tierra, porque siempre podrá decirse que la disminución de tierras disponibles pone en peor situación a todos cuantos desean poseer terrenos en propiedad" (Rothbard 1995, 330).

Esta crítica de Rothbard es sorprendente, considerando las distinciones que hace Nozick a propósito de los distintos sentidos de "empeorar". De hecho, Nozick rechaza expresamente la posibilidad de adoptar la estipulación en el sentido fuerte por la misma razón que aduce Rothbard para descartar la estipulación en general. Pero más allá de que a Rothbard se le escape el sentido de la distinción que Nozick hace, al rechazarla Rothbard demuestra no entender tampoco la función que cumple la estipulación. Y lo dicho a propósito de la crítica de Rothbard vale para todos los demás libertarios que rechazan la estipulación: una teoría de la propiedad que no contempla un modo de salvar los derechos del que se encuentra en estado de necesidad es una teoría insostenible.

Por el lado de sus detractores igualitarios, la crítica es que la estipulación resulta insuficiente o que, habiendo versiones más estrictas de cláusulas disponibles, Nozick se decante por una versión débil (Va-

5 Decimos "escasez dramática" y no "escasez" a secas, pues la virtud de la justicia sólo es posible, como observa Hume, si el primer tipo de escasez es raro y no la regla general. Y otro tanto ocurre con la abundancia total, que vuelve dicha virtud superflua (Hume 1993, 51 y ss). Esto, como se sabe, es lo que Rawls ha llamado las "circunstancias de la justicia". 
llentyne 2011, 161). Pero si se admite que la comunidad originaria es negativa y no positiva, ¿qué necesidad podría haber para establecer una cláusula más estricta? Si se partiera de una comunidad originaria positiva, uno podría imaginar a los individuos enfrentados a la necesidad de negociar el reparto de los bienes o, en su defecto, a cumplir con una estipulación más fuerte (que condujera a un resultado semejante al de una negociación). Pero si no es necesario ni pertinente partir de la hipótesis de una comunidad originaria positiva (y no lo es), es difícil ver la necesidad de introducir una versión "más fuerte" de la cláusula. Antes de los actos que realizan y de los contratos que celebran entre sí, los individuos tienen sobre los bienes externos únicamente expectativas y no derechos. En este sentido, no existe una obligación jurídica de procurar el bienestar o la felicidad de otros.

Evidentemente, se puede estar en desacuerdo con la concepción general del derecho y de la política que sirve de sustento a esta última afirmación, esto es, que a ambos sólo incumben ciertas formas de relación entre los individuos: aquéllas en que uno puede ejercer legítimamente la fuerza en contra de otro (Nozick 1988, 44; 1981, 503; 2001, 161 y ss.). Ésta es ciertamente una línea de discusión abierta con el libertarismo. Con todo, en una teoría histórica de la propiedad es difícil adivinar cómo se podrían generar obligaciones jurídicas recíprocas más estrictas que aquellas que considera Nozick sin apelar a una comunidad originaria positiva.

\section{PRINCIPIO DE JUSTICIA EN LAS TRANSFERENCIAS}

El principio general que formula la teoría del título válido a propósito de las transferencias es que éstas son justas cuando son realizadas de modo libre y voluntario, y cuando aquellos que la celebran tienen derecho (esto es, son dueños) de aquello de que disponen. Este principio no se ve alterado por la multiplicación de las transferencias ni por las consecuencias inintencionadas - la desigualdad emergente - que resulten de ese tipo particular de intercambios.

La razón fundamental es que, por grandes que sean las diferencias de patrimonios resultantes, si el conjunto total de los intercambios ha sido realizado válidamente, entonces no hay, según los propios términos de la teoría, injusticia, aun cuando la distribución resultante pueda ser 
deplorable por otras razones. La única (e importante) salvedad es, nuevamente, la condición impuesta por la estipulación de Locke. Nozick afirma que la estipulación se aplica no sólo a las adquisiciones originarias, sino también a los intercambios sucesivos, pues dichos intercambios podrían empeorar — en el sentido antes indicado — la situación de un individuo.

Por consiguiente, el principio de justicia en las transferencias comprende también la situación de aquellos que padecen necesidad sin culpa de su parte y como consecuencia directa de los intercambios que otros han realizado. Ahora bien, ¿es esta consideración suficiente o el umbral impuesto por la estipulación es demasiado bajo? ¿No pueden acaso ser las desigualdades resultantes de múltiples intercambios voluntarios injustas o reflejar un fenómeno de injusticia emergente?

Cohen ha impugnado la teoría del título válido de Nozick precisamente por las dificultades suscitadas por este problema. En relación con el ejemplo de Wilt Chamberlain, Cohen razona aproximadamente así: en efecto, los individuos que pagan directamente al famoso deportista para verlo jugar lo hacen de manera voluntaria. El problema se origina cuando la suma de pagos alcanza el nivel crítico en el cual el poder que (en virtud de su riqueza) Wilt Chamberlain adquiere sobre todos los demás, espectadores de su juego o no, es mucho, desproporcionadamente mayor, que el que tienen éstos sobre él (Cohen 1995, 23).

Este poder pone a los últimos a merced de Wilt Chamberlain y, en fin, los deja expuestos a la explotación (Cohen 1995, 25-28). De este modo, puede llegar a ocurrir que, en razón de su desmejorada posición, aunque los individuos sean formalmente libres de contratar o no con alguien poderoso (como Wilt Chamberlain), puede que en los hechos, no lo sean (esto es, no sean materialmente libres) y se vean obligados a hacerlo a cambio de un salario de subsistencia o en otras condiciones igualmente ignominiosas.

En conclusión — prosigue Cohen —, "para que prevalezca la verdadera libertad o autonomía debe haber restricciones a la disposición de sí (self-ownership)" (Cohen 1995, 102 y ss.). Esto no quiere decir, explica, impedir directamente la libertad de contratación, sino admitir la necesidad de incorporar mecanismos redistributivos que aseguren la igual libertad (en el sentido material) de todos (Cohen 1995, 100 y ss.).

Dicho de otro modo, las limitaciones a la libertad de los contratantes no suponen para Cohen que sea necesario rechazar in toto la teoría 
del título válido y suprimir con ello el mercado. Por el contrario, Cohen admite que eso no es posible ni tampoco deseable (Cohen 1995, 50). A Cohen le basta - y es una meta bastante modesta para un "marxista" analítico - con demostrar que la asignación de bienes que se realiza mediante los intercambios en el mercado no basta para garantizar la justicia y que, por tanto, son necesarios principios adicionales a los propuestos por Nozick - al menos uno - para alcanzarla.

Esta crítica de Cohen apunta al conocimiento que tienen los agentes de las consecuencias de sus propios actos. Cohen sugiere que, de conocerlas, muchos agentes habrían obrado de otra manera, es decir, no habrían pagado para ver jugar a Wilt Chamberlain (Cohen 1995, 22). El punto que le preocupa a Cohen - la enorme disparidad de poder resultante - es comprensible, pero - y dejando a un lado el problema de si acaso los efectos perniciosos de dicha disparidad pueden quedar, eventualmente, parcial o totalmente anulados por la aplicación de la estipulación de Locke- ¿en qué sentido puede decirse que esta suposición constituye una objeción a la teoría del título válido? Es cierto que los agentes económicos obran siempre con un conocimiento fragmentario o parcial, pero difícilmente eso puede constituir una objeción a la teoría del título válido. Si yo no sabía que usted iba a usar la computadora que le vendí para cometer delitos informáticos, de ahí no se sigue que la compraventa deba considerarse nula si, de haberlo sabido, yo no hubiera consentido en la venta.

Por lo demás, el problema del conocimiento parcial se repite en todos los contextos de acción: no existe una situación en que los agentes obren con el conocimiento de todas las condiciones relevantes ni menos una en la que puedan avizorar todas las consecuencias de sus actos (después de todo, la tragedia y la literatura en general deben su existencia a este hecho). Por lo mismo, si lo que Cohen quiere decir es que los agentes no obraron en realidad voluntariamente, entonces, según eso, será difícil decir de cualquier acción que es voluntaria, pues si la exigencia epistémica se eleva demasiado no podría predicarse la libertad de ningún acto.

Aunque Cohen tiene un punto al llamar la atención acerca de la situación de desamparo en que pueden quedar algunos como consecuencia de los intercambios libres, su modo de respaldarlo — presumir ex post la voluntad "verdadera" de los contratantes - es poco convin- 
cente e introduce más dificultades de las que pretende solucionar (¿qué pasaría con los intercambios si se admitiera el argumento de Cohen?). En ese sentido, su protesta parece más bien motivada por nuestra propia finitud que por la teoría del título válido de Nozick.

Quizás sería mejor interpretar la fuerte resistencia de Cohen a la teoría del título válido no como anclada en un problema cognitivo ("usted no conoce verdaderamente las consecuencias que se seguirán de la celebración de este intercambio"), sino como anclada en un problema volitivo. Es verosímil suponer que hay situaciones en que una persona, impulsada por la necesidad (pero no al punto de poder invocar la estipulación de Locke), contrata en parte voluntariamente y en parte involuntariamente. Esto es lo que Aristóteles $-\mathrm{y}$ luego la escolásticallamó el acto mixto de voluntario con involuntario (Ética a Nicomaco, Libro III, 1). Vitoria, por ejemplo, dice a propósito de la justicia de la compraventa: "en las conmutaciones humanas no es suficiente para la justicia conmutativa el que por ambas partes sea algo absolutamente voluntario, sino que es necesario que no tenga mezclado algo de involuntario"; y de inmediato añade: "aquello que se hace por necesidad, aunque sea absolutamente voluntario, sin embargo tiene añadido algo de involuntario" (Vitoria 2006, 92). Es decir, mientras mayor la involuntariedad (expresada en reticencia, resignación, etcétera), menos justo es el intercambio. ${ }^{6}$ Es importante, no obstante, enfatizar que, aunque barrunta esta posibilidad, Cohen no le saca partido e insiste en levantar el reparo epistémico ya apuntado. Y ello pese a que, por otra parte, ésta puede constituir la objeción interna más seria a la teoría del título válido.

Si además la falta de voluntariedad no puede ser subsanada por medio del principio de rectificación (ya sea porque, siendo significativa, la involuntariedad no es sin embargo tanta como para poder demandar la nulidad del contrato, ya porque, en fin, su aplicación universal requeriría revertir demasiados contratos haciendo con ello imposible el comercio), entonces uno podría considerar necesario, en los términos de la misma teoría, imponer una pauta o, en fin, darle mayor alcance al principio de rectificación a través de ciertas políticas redistributivas. Volveremos en seguida sobre este asunto.

\footnotetext{
${ }^{6}$ Con todo, compárese la posición de $\operatorname{Nozick}(1988,255$ y ss.).
} 
Otro modo de interpretar las prevenciones de Cohen frente a la teoría de Nozick es suponer que éstas se ven motivadas por lo que ha planteado, por ejemplo, Nancy Fraser (2006), esto es, el perjuicio sistemático que el capitalismo (o "libre mercado", los usaremos como sinónimos para simplificar) supone para ciertos grupos de individuos. Aquí no podemos entrar en este tema, que excede con mucho los propósitos de este trabajo. Como fuere, es claro en primer lugar que el marxismo y el socialismo de la tradición analítica no plantean el problema de la explotación en los mismos términos que Marx. Es innegable que, como observa Fraser, la estructura social, económica y política de nuestras sociedades actuales perjudica de modo sistemático a algunas personas en virtud de ciertas características raciales, sexuales, o en virtud de su filiación religiosa, entre otras. Pero esa constatación, que constituye el factum del que parte la propuesta socialista de Fraser, queda muy lejos de la idea de la lucha de clases y de la consideración exclusiva del proletariado como sujeto de la explotación capitalista.

En segundo lugar, es claro que este concepto "ampliado" de "proletariado" - y la constatación de los perjuicios que sufre - suscita un desafío al libertarismo que puede plantearse así: ¿tiene el libertarismo algún recurso conceptual para examinar críticamente la situación de injusticia que Fraser denomina de "déficit de reconocimiento"?

En cierto sentido la respuesta es "no", pues el libertarismo no cuenta con dispositivos legales ni institucionales para hacer frente a las situaciones de discriminación informal y sistemática que ellos denuncian. El principio de rectificación, por su parte, no es suficiente para justificar la adopción de medidas de discriminación positiva y sólo entra en juego si la discriminación es fruto de privilegios o de cargas impuestas por el Estado.

Sin embargo, desde otra perspectiva, el ethos libertario ofrece un espaldarazo a aquellas minorías que adolecen de déficit de reconocimiento, en la medida en que la idea fundacional del libertarismo - en línea con el liberalismo clásico- es la defensa de los más diversos modos de vida $\mathrm{o}$, expresado en términos más enfáticos, la promoción y defensa de la idea de que cada individuo tiene la libertad de vivir su vida como prefiera mientras con ello no perjudique la libertad equivalente que tienen todos los demás. 
No creo que sea exagerado afirmar que Nozick tiene el mérito de haber defendido sin titubeos ni vacilaciones esta idea que considera la base de la única utopía libertaria posible. Dicha utopía propugna el reconocimiento implícito de todas las formas de vida que puedan ajustarse al principio de coexistencia de libertades recién mencionado. Este reconocimiento implícito es reflejo de la virtud liberal de la tolerancia, $\mathrm{y}$, bien entendido, la teoría del título válido descansa en el principio subyacente a ese reconocimiento implícito - la idea de que cada uno pueda escoger el género de vida que mejor le parezca- y no al revés.

Y a propósito de la utopía libertaria, es posible abordar el problema de la diferencia entre el ideal de la sociedad de intercambio libre y el capitalismo real. Los detractores del libertarismo suelen considerar al capitalismo como el causante de la discriminación, expolio e injusticia sistemática de que son víctimas ciertos grupos (por ejemplo, las mujeres y minorías étnicas). Pero al respecto convendría subrayar el carácter más bien ambivalente que tiene el mercado en los procesos de explotación y emancipación de grupos como los mencionados, al socavar lenta pero inexorablemente relaciones patriarcales, feudales y otras basadas en la autoridad o en atavismos de distinto tipo. Como observaran ya Marx y Engels (2011, cap.1), el proceso capitalista profana lo sagrado, derriba tabúes y convierte todo en un objeto de transacción y, con ello (podríamos añadir), en objeto de elección individual. De ahí que, como crudamente dijera Lemebel a modo de reproche a sus camaradas comunistas, "[e]n Nueva York los maricas se besan en la calle" (Lemebel 2013, 38).

Finalmente, no debe perderse de vista que la teoría del título válido es una teoría que pretende dar con las condiciones justas de la adquisición e intercambio de bienes, no describir ni justificar el sistema capitalista tal cual es. En ese sentido, como la de Rawls, la teoría de la justicia de Nozick pretende describir lo que debería haber ocurrido para que nuestra organización social y política fuera justa (ni más ni menos), no lo que de hecho ocurre.

Por eso, al momento de formular la teoría del título válido, Nozick emplea el condicional: "[s]i el mundo fuera completamente justo..." $(1988,154)$. Pero el mundo no es nunca completamente justo porque nosotros no lo somos, de modo que el ideal del mercado perfectamente libre (y de la sociedad perfectamente libre en que se basa) habrá de per- 
manecer como una utopía que puede servir para encaminar nuestros esfuerzos en el devenir del mundo tal cual es. Aunque Nozick no plantea las cosas de ese modo, deja abierta la posibilidad de considerarlas así, desde el momento en que hace el contraste entre la situación ideal de intercambio y el capitalismo "realmente existente":

El ideal capitalista de comercio libre y voluntario, productores compitiendo para servir a las necesidades de los consumidores en el mercado, individuos siguiendo su propia inclinación sin interferencia externa coercitiva, naciones relacionándose cooperativamente en el comercio, cada individuo recibiendo lo que otros que lo han ganado optan por otorgar a cambio de un servicio, sin que unos impongan sacrificios sobre otros, ha servido como pretexto para otras cosas: depredación internacional, compañías sobornando a gobiernos extranjeros o locales por privilegios especiales que les permiten evitar la competencia y explotar una posición ventajosa, la instalación de regímenes autocráticos —a menudo basados en la tortura - que rigen este mercado privado delimitado, guerras para ganar recursos o territorios de mercado, la dominación de los trabajadores por los supervisores o empleadores, compañías manteniendo en secreto efectos nocivos de sus productos o procesos de manufacturación, etcétera. Este es el lado malo del ideal capitalista en la realidad. No es toda la historia de este ideal; también hay producción y comercio libre y voluntario, ganancias individuales y demás. Pero es parte de la historia. (Nozick 1992, 222-223)

\section{PRINCIPIO DE RECTIFICACIÓN}

En virtud de la brecha entre el ideal de la sociedad perfectamente libre y el capitalismo "realmente existente", sería de esperar que el "principio de rectificación", que tiene por finalidad lidiar con dicha brecha, tuviera un tratamiento mucho más acabado en la exposición de la teoría.

Sin embargo, Nozick apenas le dedica unas líneas. Es de suponer que esa parquedad se debe a que, como seguramente avizora, cualquier tratamiento sistemático del principio de rectificación bajo las condiciones del capitalismo "realmente existente" debiera llevar a sostener la necesidad de un Estado más que mínimo que dispusiera de las medidas 
compensatorias pertinentes, ${ }^{7}$ postergando con ello sine die la instauración del Estado mínimo.

En cambio, Nozick afirma demasiado alegremente que la aplicación del principio de rectificación podría justificar un Estado mayor que el Estado mínimo "brevemente". Dicho optimismo se explica, de seguro, por el carácter polémico de la obra y porque Nozick quiere despejar de antemano cualquier deriva "socialista" de su propia teoría ("el socialismo como castigo por nuestros pecados sería ir demasiado lejos", dice en 1988, 227), lo que evidentemente constituye una exageración, dadas las alternativas, los grados que existen entre el Estado mínimo y el socialismo que tanto preocupa a Nozick.

Como fuere, aunque breves, las líneas que Nozick dedica al principio de rectificación son muy significativas. La regla general que se sigue de la teoría del título válido en relación con la extensión del Estado puede resumirse diciendo que: "[s]i el conjunto de pertenencias es generado apropiadamente, no hay ningún argumento en favor de un Estado más extenso basado sobre la justicia distributiva" (Nozick 1988, 226). Evidentemente, y como se adelantaba, no cualquier injusticia repercute en el tamaño del Estado. Muchas injusticias pueden subsanarse mediante una simple restitución. Las injusticias repercuten en el tamaño y las funciones del Estado (en el sentido de obligarlo a realizar funciones redistributivas) sólo cuando adquieren cierto alcance y entidad, cuando tienen una proyección histórica y sistémica, de suerte que gran parte de los títulos de propiedad son viciosos o dudosos.

Evidentemente, no hay modo de fijar a priori la concurrencia de todas esas condiciones y es necesario aplicar razonamientos prudenciales (además de los despojos a los aborígenes americanos, se puede citar el caso de los descendientes de esclavos afroamericanos y de las minorías étnicas o nacionales víctimas de las aventuras imperialistas de otros; esta última posibilidad también abre la posibilidad de que existan responsabilidades entre Estados). En vista de las dificultades suscitadas por ese tipo de injusticias, Nozick afirma que:

Quizá sea mejor considerar algunos principios pautados de justicia distributiva como burdas reglas prácticas, hechas para aproximar los resultados generales de la aplicación del principio de

\footnotetext{
${ }^{7}$ Para el concepto de “compensación”, ver Nozick (1988, 65-66).
} 
rectificación de injusticia. Por ejemplo, a falta de mucha información histórica y suponiendo: 1) que las víctimas de la injusticia se hallan peor de lo que de otra manera estarían, y 2) que los del grupo menos bien situado en la sociedad tienen las mayores probabilidades de ser (los descendientes de) las víctimas de las injusticias más graves, a quienes les es debida una compensación por aquellos que se beneficiaron de las injusticias (suponiendo que sean los mejor situados, aunque, algunas veces, los perpetradores de la injusticia serán otros del grupo de los peor situados), entonces una burda regla práctica para rectificar las injusticias podría ser, al parecer, la siguiente: organizar a la sociedad en forma que maximice la posición de cualquier grupo que resulte menos bien situado en ella. (Nozick 1988, 226-227)

Al leer este pasaje resulta inevitable no pensar en la teoría de la justicia de Rawls, y particularmente en el principio de diferencia, en el que de seguro Nozick estaba pensando. Esta asociación se ve reforzada además por una indicación que se encuentra en una nota al pie de $A S U$, referida a los posibles esquemas de compensación a que podría conducir el principio de rectificación a partir de una situación particular dada: puesto que el principio debe ser aplicado, ante dos esquemas alternativos de compensación, "tal vez la clase de consideraciones sobre la justicia distributiva y la igualdad, que yo ataco, desempeñe un papel ilegítimo en esta opción subsidiaria" (Nozick 1988, 156).

Dicho de otro modo, ante la dificultad de encontrar el esquema de rectificación correcto, puede que las consideraciones igualitaristas ofrezcan, subsidiariamente, el modelo adecuado de compensación. En virtud de estas consideraciones, resultaría pertinente preguntarse si, dada la brecha entre la situación ideal de adquisición e intercambio y el desarrollo histórico efectivo que ha conducido a la distribución actual de bienes, la aplicación de los principios libertarios no debiera conducir invariablemente a un esquema histórico y pautado de distribución cuya pauta favorezca de modo sistemático a los grupos más desaventajados, que generalmente lo son por causa de injusticias históricas.

De ser así, el esquema general de la teoría del título válido sería semejante al de Rawls, aun cuando las vías para arribar a ello (y seguramente también su alcance) serían evidentemente diferentes. En este sentido, la teoría posible de Nozick —o su aplicación consistente, si se 
quiere - tiene, nuevamente, resultados menos contraintuitivos de los que los críticos — alentados por el mismo Nozick, por cierto- suelen suponer. ${ }^{8}$

En vista de las consecuencias sistemáticas del principio de rectificación, resulta extraño, hasta cierto punto, que muchos de los detractores de Nozick no hayan explotado las posibilidades en favor del Estado-más-que-mínimo a partir de dicho principio. "Hasta cierto punto" porque, por otra parte, esa renuencia puede explicarse por la resistencia a argumentar desde la propia teoría de Nozick, dando con ello por bueno los principios de la teoría del título válido. Con todo, dichos detractores podrían admitir al menos que, de hecho, el principio de rectificación apunta a remediar muchas de las injusticias que a ellos mismos les preocupan.

\section{CONCLUSIONES}

Muchos de los argumentos contra la teoría del título válido - la mayoría de ellos - son francamente débiles. El hecho, por otra parte, de que muchas objeciones sean febles no quita que la teoría presente dificultades, más en la aplicación e interpretación de sus propios principios que en la formulación de los mismos. En este sentido, además de responder a algunas de dichas críticas, aquí se ha intentado indicar el contenido que podría haber tenido la segunda parte de $A S U$, es decir, un curso posible del libertanismo de Nozick, curso que, no cabe duda, habría moderado el tono y las tesis del libro, haciéndolo menos audaz, provocador $y$, posiblemente, también menos atractivo.

Con todo, este ejercicio permite demostrar, por una parte, la plausibilidad general de la teoría del título válido que, como el mismo Nozick insinúa, refleja los criterios bajo los cuales tendemos efectivamente a atribuir las cosas a cada uno; por otra, permite demostrar que una consideración realista y con sentido histórico de los principios libertarios debiese conducir - y no tan sólo por un "lapso breve" - a un Estado mayor que el Estado mínimo (después de todo, ¿cómo se resarcen, por ejemplo, injusticias doscientos, trescientos o quinientos años después de cometidas?).

${ }^{8}$ Lomasky (2005) y Waldron (2005) han llamado la atención acerca de la posibilidad. 
Pero ¿qué tipo de Estado? De seguro no un Estado de bienestar (y aquí se encuentra la piedra de toque entre la filosofía política de Rawls y la de Nozick); sí quizá alguna de las variantes del Estado subsidiario, en la medida en que éstas sirvan como vehículo suficiente de ejecución del principio de rectificación. Por lo demás, sólo esta última versión podría llegar a ser compatible con la noción de Nozick de los derechos individuales y con su idea - expresada de modo desafortunado por lo que toca al estado de necesidad recogido en la cláusula de Locke- de que dichos derechos deben ser co-posibles y configuran el medio externo en el que se desenvuelven los individuos (Nozick 1988, 255).

La consideración de la brecha que existe entre los presupuestos ideales de la teoría y sus condiciones reales de aplicación nos ha llevado a otorgar más peso al principio de rectificación del que el mismo Nozick le otorga. Esta interpretación salva a la teoría del título válido de las consecuencias contraintuitivas que se le achacan -algunas atribuibles ciertamente al propio Nozick-, al precio de renunciar a su radicalidad. ¿Se ha traicionado con ello la teoría del título válido? No, si se entiende - como el propio Nozick en una etapa más madura de su pensamiento - que, como en todo lo demás, en filosofía política la renuncia a la radicalidad constituye el precio de la verosimilitud. Si dicha renuncia constituye o no también una victoria pírrica, es algo que el propio lector debe juzgar.

\section{REFERENCIAS CITADAS}

Aristóteles. Ética a Nicómaco. 2002. Traducido por María Araujo \& Julián Marías. Madrid: Centro de Estudios Políticos y Constitucionales.

Barry, Brian. 1997. Justicia como imparcialidad. Traducido por José Pedro Tosaus. Barcelona: Paidós.

Cohen, Gerald A. 1995. Self-ownership, Freedom and Equality. New York: Cambridge University Press.

- 2014. Por una vuelta al socialismo. O cómo el capitalismo nos hace menos libres. Editado por Jahel Queralt. Buenos Aires: Siglo Veintiuno.

De Soto, Domingo. 1968. De iustitia et iure libri decem - De la justicia y el derecho en diez libros, tomo II. Traducido por Marcelino González Ordóñez. Madrid: Instituto de Estudios Políticos.

Fesser, Edward. 2005. "There is no such thing as an unjust initial acquisition". En Natural Rights Liberalism from Locke to Nozick, editado por Elle Franken Paul, Fred D. Miller Jr. \& Paul Jeffrey, 56-80. Cambridge: Cambridge University Press. 
Fraser, Nancy. 2006. Artículos varios en ¿Redistribución o reconocimiento? Un debate político-filosófico, de Nancy Fraser \& Axel Honneth. Traducido por Pablo Manzano. Madrid: Fundación Paideia Galiza-Ediciones Morata.

Grey, Thomas C. 1980. "The Disintegration of Property”. Nomos XII: 69-86.

Hohfeld, Wesley Newcomb. 1964. Fundamental Legal Conceptions as Applied in Judicial Reasoning. New Haven: Yale University Press.

Honoré, A. M. 1961. “Onwership”. En Oxford Essays on Jurisprudence, editado por A.G. Guest, 107-147. Oxford: Oxford University Press.

Hume, David. 1993. Investigación sobre los principios de la moral. Traducido por Carlos Mellizo. Madrid: Alianza Editorial.

Kant, Immanuel. 1910-1917; 1923-1972. Kants Gesammelte Schriften herausgegeben von der Königlich Preussischen Akademie der Wissenschaften. Vols. I-XXVIII. Berlin, Leipzig: Georg Reimer; Walter de Gruyter.

Lemebel, Pedro. 2013. Poco hombre. Crónicas escogidas. Santiago: Ediciones Universidad Diego Portales.

Locke, John. 1988. Two Treatises of Government. Editado por Peter Laslett. Cambridge: Cambridge University Press.

Lomasky, Loren E. 2005. "Libertarianism at Twin Harvard". En Natural Rights Liberalism from Locke to Nozick, editado por Elle Franken Paul, Fred D. Miller Jr. \& Paul Jeffrey, 178-199. Cambridge: Cambridge University Press.

Marx, Karl \& Friedrich Engels. 2011. Manifiesto comunista. Traducido por Pedro Ribas Ribas. Madrid: Alianza Editorial.

Nagel, Thomas. 1981. "Libertarianism without Foundations". En Reading Nozick. Essays on Anarchy, State and Utopia, editado por Jeffrey Paul, 191-205. Oxford: Basil Blackwell.

Narveson, Jan. 2001. The Libertarian Idea. Canada: Broadview Press.

Nozick, Robert. 1974. Anarchy, State, and Utopia. Oxford: Basic Books.

- 1981. Philosophical Explanations. Cambridge: Harvard University Press.

—. 1988. Anarquía, Estado y utopía. Traducido por Rolando Tamayo. México: Fondo de Cultura Económica.

- 1989. The Examined Life. Philosophical Meditations. New York: Simon \& Schuster.

- 1992. Meditaciones sobre la vida. Traducido por Carlos Gardini. Barcelona: Gedisa.

— 1995. La naturaleza de la racionalidad. Traducido por Antoni Domènech. Barcelona: Paidós.

- 2001. Invariances. Cambridge: Harvard University Press.

O’Neill, Onora. 1981. “Nozick’s Entitlement”. En Reading Nozick, editado por Jeffrey Paul, 305-322. Oxford: Blackwell.

Penner, James E. 1995-1996. "The 'Bundle of Rights' Picture of Property”. UCLA Review: 711-820.

Pufendorf, Samuel. 1998. Gesammelte Werke. De iure naturae et gentium. Vol. 4. Berlin: Akademie Verlag. 
Roar, Eric. 2013. Removing the Commons. Plymouth: Lexington Books.

Rothbard, Murray N. 1995. La ética de la libertad. Traducido por Marciano Villanueva Salas. Madrid: Unión Editorial.

Schwember, Felipe. 2013. "Plena in re potestas? Paradigmas y problemas en torno a la definición de la propiedad en la filosofía política y jurídica contemporánea”. Revista Telemática de Filosofía del Derecho 15: 59-104.

Tomás de Aquino. 1956. Suma Teológica. Traducido por Teófilo Urdanoz. Vol. VIII. Madrid: Biblioteca de Autores Cristianos.

Underkuffler, Laura S. 2003. The Idea of Property. Its Meaning and Power. Oxford: Oxford University Press.

Vallentyne, Peter. 2011. "Nozick's libertarian theory of justice". En The Cambridge Companion to Nozick's Anarchy, State, and Utopia, editado por Ralf M. Bader \& John Meadowcroft, 145-167. New York: Cambridge University Press.

Vitoria, Francisco de. 2006. Contratos y usura. Traducido por M. ${ }^{a}$ Idoya Zorroza. Pamplona: Eunsa.

Waldron, Jeremy. 2005. "Nozick and Locke: Filling the Space of Rights". En Natural Rights Liberalism from Locke to Nozick, editado por Elle Franken Paul, Fred D. Miller Jr. \& Paul Jeffrey, 56-110. Cambridge: Cambridge University Press.

Weinrib, Ernest J. 2003. "Poverty and Property in Kant's System of Rights". Notre Dame Law Review 78, $\mathrm{n}^{\circ}$ 3: 795-828. EP 